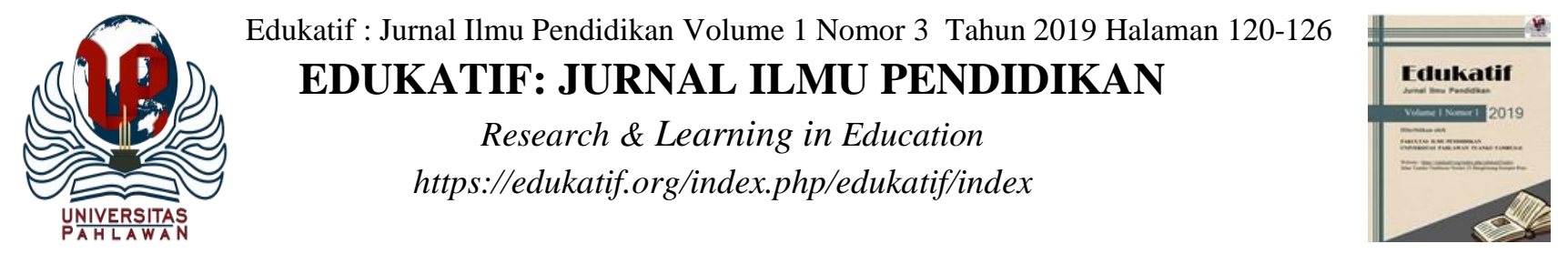

\title{
PENGUJIAN VALIDITAS MODUL INTERAKTIF SIMULASI DAN KOMUNUKASI DIGITAL BERBASIS MACROMEDIA DIRECTOR MX
}

\author{
Rina Sepriana ${ }^{1}$, Rini Sefriani $^{2}$, Indra $\mathrm{Wijaya}^{3}{ }^{3}$ Pipit Lestari $^{4}$ \\ Universitas Putra Indonesia Yptk Padang, Sumatera Barat, Indonesia ${ }^{1234}$

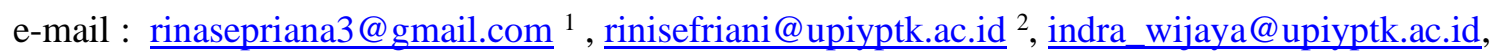 \\ pipitlestary94@gmail.com ${ }^{1}$
}

\begin{abstract}
Abstrak
Penelitian ini bertujuan untuk mengetahui tingkat uji validitas produk berupa Media Pembelajaran Modul Multimedia Interaktif Berbasis Macromedia Director MX untuk Kelas X di SMK-SMAK Padang. Penelitian ini Menggunakan metode penelitian pengembangan Research and Development (R\&D). Validasi dilakukan oleh validator ahli media, ahli materi dan ahli multimedia. Penilaian dari validator untuk Media Pembelajaran Modul Multimedia Interaktif Berbasis Macromedia Director MX di tinjau dari aspek (1) Kelayakan isi diperoleh rata - rata sebesar 90.4\%; (2) Komponen Kebahasaan diperoleh rata - rata sebesar 91,00\%; (3) Komponen Penyajian diperoleh rata - rata $89.5 \%$; (4) Komponen Kegrafikan diperoleh rata - rata $90.3 \%$. . Secara Keseluruhan Penilaian uji validator terhadap Media Pembelajaran Modul Multimedia Interaktif Berbasis Macromedia Director MX diperoleh rata-rata secara keseluruhan sebesar 90,35\%, sehingga tingkat validitas dapat di interprestasikan sangat valid digunakan sehingga Media Pembelajaran Modul Multimedia Interaktif Berbasis Macromedia Director MX untuk Kelas X di SMK-SMAK Padang diinterpretasikan sangat valid di gunakan. Berdasarkan penilaian beserta masukan ahli serta hasil dari uji coba lapangan media pembelajaran Modul Multimedia Interaktif Berbasis Macromedia Director MX dapat disimpulkan sudah teruji kelayakannya.
\end{abstract}

Kata Kunci: Modul Interaktif, Macromedia Director MX, Simulasi dan komunikasi digital

\begin{abstract}
This study aims to determine the level of product validity testing in the form of Interactive Multimedia Learning Media Based on Macromedia Director MX for Class X in SMK-SMAK Padang. This research uses research and development research and development $(R \& D)$ methods. Validation is carried out by validators, media experts, material experts and multimedia experts. Evaluation from validator for Learning Media Interactive Multimedia Module Based on Macromedia Director MX in terms of aspects (1) Content worthiness is obtained by an average of $90.4 \%$; (2) the linguistic component is obtained an average of 91.00\%; (3) Presentation Components obtained an average of 89.5\%; (4) The components of the graphics are 90.3\% on average. . Overall validator test assessment of Interactive Multimedia Module Learning Media Based on Macromedia Director MX obtained an overall average of $90.35 \%$, so that the level of validity can be interpreted very validly used so that Learning Media Interactive Multimedia Module Based on Macromedia Director MX for Class X in Padang Vocational High School is interpreted to be very valid in use. Based on the assessment along with expert input and the results of the field testing of learning media Interactive Multimedia Module Based on Macromedia Director MX, it can be concluded that the feasibility has been tested.
\end{abstract}

Keywords: Interactive Module, Macromedia Director MX, Simulation and digital communication.

@Edukasi: Jurnal Ilmu Pendidikan FIP UPTT 2019

$\triangle$ Corresponding author :

Address :

Ema :

ISSN 2656-8063 (Media Cetak)

Phone

ISSN 2656-8071 (Media Online) 
121 Pengujian validitas modul interaktif simulasi dan komunikasi digital berbasis macromedia director MX- Rina Sepriana, Rini Sefriani, Indra Wijaya, Pipit Lestari

\section{PENDAHULUAN}

Kedudukan alat bantu memiliki peranan yang penting karena dapat membantu proses belajar siswa. Banyak alat bantu atau media belajar diciptakan untuk belajar mandiri saat ini, namun untuk mencari suatu pilihan atau solusi alat bantu yang benar-benar baik agar proses belajar menjadi efektif, menarik dan interaktif serta menyenangkan merupakan suatu permasalahan yang perlu dicari solusinya. Pada penelitian yang dilakukan (Indra Wijaya, 2017) menyatakan bahwa diantara solusi media dalam membantu proses pembelajaran adalah dalambentuk modul interaktif.

Alat bantu atau media pembelajaran dibuat dan dapat digunakan sesuai dengan tujuan pembelajaran. Pembelajaran yang cenderung bersifat hafalan mungkin cukup hanya dengan memakai buku panduan. Lain halnya dengan pembelajaran yang cenderung ke arah praktek yang membutuhkan informasi tambahan. Pembelajaran praktekmemvisualkan suatu bahan ajar terkadang mengalami hambatan yang di sebabkan oleh keterbatasan pengajar, peralatan, alat, bahan, biaya dan sebagainya di mana proses penyampaian informasi tidak cukup hanya dengan penyampaian secara ceramah. (Indra Wijaya, 2016) mengatakan bahwa dengan adanya media interaktif dalam proses pembelajaran akan membantu siswa dalam melaksanakan materi praktek. Popi rdayuli (2019) melakukan penelitian juga menyimpulkan bahwa alat bantu dalam bentu media pembelajaran dapat menigkatkan hasil belajar siswa dan membantu siswa dalam proses pembelajaran.

Kaitannya dengan pengajar, terkadang pengajar sebagai penyampai informasi kepada siswa kurang bisa menciptakan suasana belajar yang menarik dan kondusif. Dengan pemakaian Modul Pembelajaran untuk Mata Pelajaran Simulasi dan Komunikasi Digital (SIMKOMDIG) ini juga diharapkan dapat membantu disaat guru tidak bisa hadir untuk menyampaikan materi di dalam kelas seperti biasanya (Rini Sefriani, 2018) mengatakan dalam peneltiiannya bahwa suasana belajar dapat menjadi kondusif dan menarik dengan dihadirkannya media dalam bentuk modul pembelajaran interaktif.

Modul merupakan bahan ajar yang disusun secara sistematis dengan bahasa yang mudah dipahami oleh siswa, sesuai usia dan tingkat pengetahuan mereka agar mereka dapat belajar secara mandiri dengan bimbingan minimal dari pendidik (Andi Prastowo, 2012: 106). Penggunaan modul dalam pembelajaran bertujuan agar siswa dapat belajar mandiri tanpa atau dengan minimal dari guru (Lika Jafnihirda, 2019) . Di dalam pembelajaran, guru hanya sebagai fasilitator. Simulasi dan Komunikasi Digital (SIMKOMDIG) merupakan salah satu bidang studi dan disiplin ilmu yang diajarkan di sekolah, termasuk di SMK-SMAK Padang. Tujuan pembelajaran Teknologi Informasi dan Komunikasi itu sendiri adalah untuk mengembangkan keterampilan dalam memanfaatkan teknologi informasi dan komunikasi.

Proses pembelajaran SIMKOMDIG seharusnya siswa aktif belajar sehingga mempunyai kemampuan untuk mengembangkan kreativitasnya dalam menyelesaikan soal-soal atau permasalahan. Siswa mempunyai tingkat kreativitas yang berbeda-beda, ada yang sudah mempunyai tingkat kreativitas yang tinggi namun ada juga yang masih rendah, sehingga kemampuan untuk dapat memecahkan masalah juga berbeda.Permasalahan yang ada di SMK-SMAK Padang ini adalah sistem pembelajaran masih berpusat kepada pendidik. Sehingga tingkat kreativitas siswa berjalan lambat dan frekuensi belajar menurun. Siswa cenderung lebih banyak bermain ketimbang mengikuti proses belajar mengajar. Ini dikarenakan sulitnya memahami 
122 Pengujian validitas modul interaktif simulasi dan komunikasi digital berbasis macromedia director MX- Rina Sepriana, Rini Sefriani, Indra Wijaya, Pipit Lestari

materi pembelajaran. Disamping itu sumber belajar yang digunakan siswa hanya berpatokan kepada LKS dan tidak ada modul sebelumnya. Sehingga seringkali siswa mengalami kejenuhan dalam proses belajar yang mengakibatkan hasil belajar Simulasi dan Komunikasi Digital (SIMKOMDIG) tidak maksimal. Hal ini diduga disebabkan oleh tidak adanya media pembelajaran yang menarik minat bagi belajar siswa.

Menurut Sadiman, dkk (2002:6) media sebagai segala sesuatu yang dapat di gunakan untuk menyalurkan pesan dan mengirimkan pesan kepada penerima pesan,sehingga dapat merangsang pikiran,perasaan,perhatian dan minat siswa sedemikian rupa,sehingga proses belajar mengajar berlangsung dengan efektif dan efisien sesuai dengan yang di harapkan. Hal ini senada dengan penelitian dari Rini Sefriani (2018) bahwa pembelajaran efektif dapat dilakuakn dengan menghadirkan media pembelajran interaktif yang membuat siswa dapat belajar mandiri.

Defenisi media pembelajaran secara umum adalah komponen sumber belajar atau sarana fisik yang mengandung materi instruksional di lingkungan siswa untuk belajar. Ringkasnya, media pembelajaran adalah alat untuk menyampaikan atau mengantarkan pesan-pesan pembelajaran. maka dapat disimpulkan bahwa media merupakan perantara atau alat yang digunakan untuk penyampaian pesan kepada penerima pesan. Media pembelajaran memberikan manfaat yang positif dalam pembelajaran.Penggunaan media dalam pembelajaran membantu guru dalam menyapaikan materi ajar yang bersifat abstrak.

Modul pembelajaran adalah bahan ajar yang disusun secara sistematis dan menarik mencangkup isi materi, metode dan evaluasi yang dapat digunakan secara mandiri untuk mencapai kompetensi yang diharapkan (Anwar, 2010:52). Popi Radyuli (2019) dalam penelitian mengatakan bahwa dengan adanya alat bantu dalam pembelajaran dapat menigkatkan hasil belajar siswa . Menrisal ( 2018) juga menyatakan bahwa dengan adanya modul interaktif dapat meningkatkan hasil belajar siswa

Merupakan sebuah aplikasi perangkat lunak yang bergerak dibidang grafis dan pengembangan Web. aplikasi yang digunakan untuk membuat Modul Multimedia Interaktif Berbasis Macromedia Director MX pada mata pelajaran Simulasi dan Komunikasi Digital.

Simulasi dan Komunikasi digital merupakan mata pelajaran yang membekali para siswa agar dapat menkomunikasikan gagasan (ide) pemikiran atau konsep melalui media dgital. Simulasi Digital adalah proses belajar dengan menggunakan Teknologi Informasi dan Komunikasi (TIK) melalui pengembangan bahan ajar berbasis Web.

\section{METODE}

Penelitian ini menggunakan penelitian dan pengembangan atau biasa disebut dengan $R \& D$ (research and development),yaitu metode penelitian yang digunakan untuk menghasilkan produk tertentu, dan menguji keefektifan produk tersebut. Penelitian dan pengembangan adalah suatu proses atau langkah-langkah untuk mengembangkan suatu produk baru atau menyempurnakan produk yang telah ada, Produk yang dihasilkan tersebut tidak selalu berbentuk benda seperti buku, alat tulis, dan alat pembelajaran lainnya. Namun dapat pula dalam bentuk perangkat lunak (software).

Model perancangan media yang digunakan yang mengacu pada jenis perancangan four- $D$ models yang terdiri dari 4 tahap yaitu Define (pendefinisian), Design (perancangan), Develop (pengembangan) dan Dessiminate (penyebaran) 
123 Pengujian validitas modul interaktif simulasi dan komunikasi digital berbasis macromedia director MX- Rina Sepriana, Rini Sefriani, Indra Wijaya, Pipit Lestari

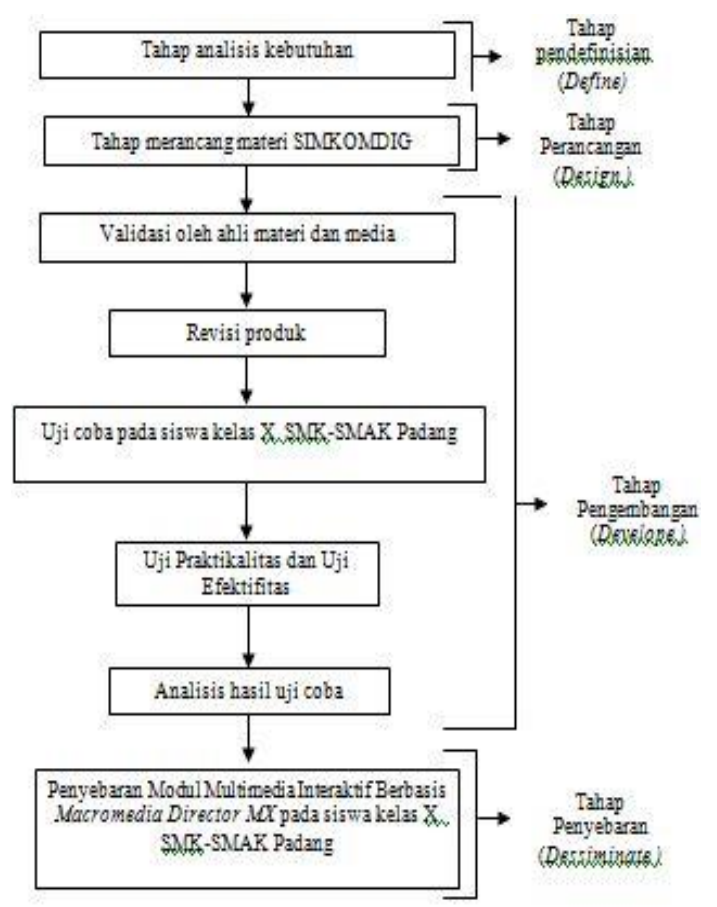

Gambar 1. Pengembangan Four-D Model

Jenis data yang diambil dalam penelitian ini adalah data primer. Data pertama berupa hasil validasi Modul pembelajaran berbasis Macromedia Director $M X$ yang diberikan oleh validator. Data kedua diperoleh dari pelaksanaan uji coba Modul pembelajaran berbasis Macromedia Director MX. Pada uji coba Modul pembelajaran berbasis Macromedia Director MX ini di ambil berupa, (1) hasil observasi pelaksanaan pembelajaran menggunakan Modul pembelajaran berbasis Macromedia Director $M X$,

(2) Respon siswa terhadap media pembelajaran berbasis Macromedia Director MX yang telah di uji cobakan.

Jenis data yang diambil dalam penelitian ini adalah data primer. Data pertama berupa hasil validasi Modul Multimedia Interaktif berbasis Macromedia Director MX yang diberikan oleh validator. Data kedua diperoleh dari pelaksanaan uji coba Modul Multimedia Interaktif berbasis Macromedia Director MX. Pada uji coba Modul Multimedia Interaktif berbasis Macromedia Director $M X$ ini di ambil berupa, (1) hasil observasi pelaksanaan pembelajaran menggunakan Modul Multimedia Interaktif berbasis Macromedia Director MX, (2) Respon siswa terhadap Modul
Multimedia Interaktif berbasis Macromedia Director $M X$ yang telah di uji cobakan

Analisis Uji Validitas Modul Multimedia Interaktif berbasis Macromedia Director MX. Analisis uji validitas Modul Multimedia Interaktif berbasis Macromedia Director MX berdasarkan lembar uji validitas yang dilakukan dengan langkah sebagai berikut :

a. Memberikan skor jawaban dengan kriteria berdasarkan skala Likert yang dimodifikasi oleh Sugiyono (2014 : 93) yaitu :

Tabel 1. Penilaian Jawaban validitas

\begin{tabular}{|l|l|l|}
\hline Pilihan & $\begin{array}{l}\text { Keteran } \\
\text { gan }\end{array}$ & Bobot \\
\hline Sangat Setuju & SS & 5 \\
\hline Setuju & S & 4 \\
\hline Kurang Setuju & KS & 3 \\
\hline Tidak Setuju & TS & 2 \\
\hline Sangat Tidak Setuju & STS & 1 \\
\hline
\end{tabular}

Sumber : Sugiyono (2014: 135)

a) Menentukan skor tertinggi

Skor tertinggi $=$ jumlah validator $\mathrm{x}$ jumlah item pertanyaan $\mathrm{x}$ skor maksimum.

b) Menentukan jumlah skor dari masingmasing validator dengan menjumlahkan semua skor yang di peroleh dari masing-masing indikator.

c) Menentukan skor yang diperoleh dengan menjumlahkan skor dari masing-masing validator.

d) Penentuan nilai validitas dimodifikasi dari Purwanto (2010:102) sebagai berikut:

$N P=\frac{R}{S M} \times 100(1)$

Keterangan :

$\mathrm{NP}=$ Nilai persen yang dicari atau yang diharapkan

$\mathrm{R}=$ Skor mentah yang diperoleh siswa 
124 Pengujian validitas modul interaktif simulasi dan komunikasi digital berbasis macromedia director MX- Rina Sepriana, Rini Sefriani, Indra Wijaya, Pipit Lestari

$\mathrm{SM}=$ Skor Maksimum ideal dari tes yang bersangkutan

100 = Bilangan Tetap

e) Memberikan penilaian validitas dengan kriteria yang dimodifikasi dari Purwanto (2010 : 82) berikut ini :

Tabel 2. Klasifikasi Aspek Penilaian Validitas

\begin{tabular}{|lll|}
\hline No & Nilai & Aspek yang Dinilai \\
1 & $90 \%-100 \%$ & Sangat Valid \\
2 & $80 \%-89 \%$ & Valid \\
3 & $65 \%-79 \%$ & Cukup Valid \\
4 & $55 \%-64 \%$ & Kurang Valid \\
& & \\
5 & $\leq 54 \%$ & Tidak Valid \\
\hline
\end{tabular}

Sumber : Purwanto (2010:82)

f) Kemudian menentukan nilai distribusi frekuensi validitas yang dimodifikasi dari Prof. Dr. H. Agus I. Irianto berikut ini:

$$
\begin{aligned}
& \mathrm{R}=\text { data tertinggi }- \text { data terendah } \\
& \mathrm{K}=1+\frac{\mathrm{R}}{3} .3 \log \mathrm{n} \\
& \mathrm{P}=\frac{\mathrm{K}}{}
\end{aligned}
$$

Keterangan :

$\mathrm{P}=$ Panjang kelas interval

$\mathrm{R}=$ Hitung jarak atau rentangan

$\mathrm{K}=$ Jumlah kelas

\section{HASIL DAN PEMBAHASAN}

Halaman Login Password merupakan halaman yang pertama tampil ketika anda membuka Modul Multimedia Interaktif. Login Password pada Modul Interaktif ini adalah sebagai proses masuk ke halaman awal modul multimedia interaktif dengan memasukan identitas acount minimal terdiri dari user name atau akun pengguna dan password untuk mendapatkan hak akses.

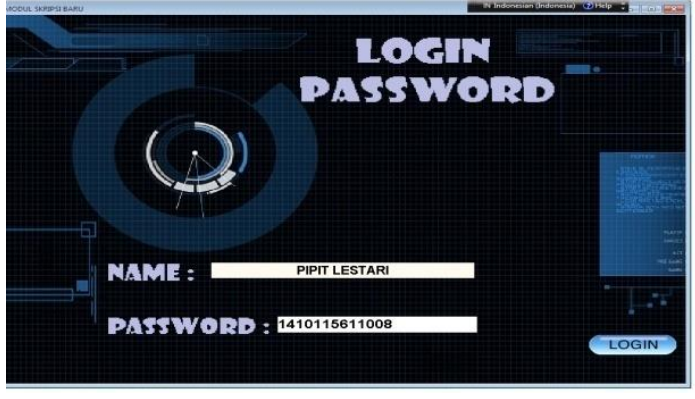

Gambar 2. Halaman Login Password

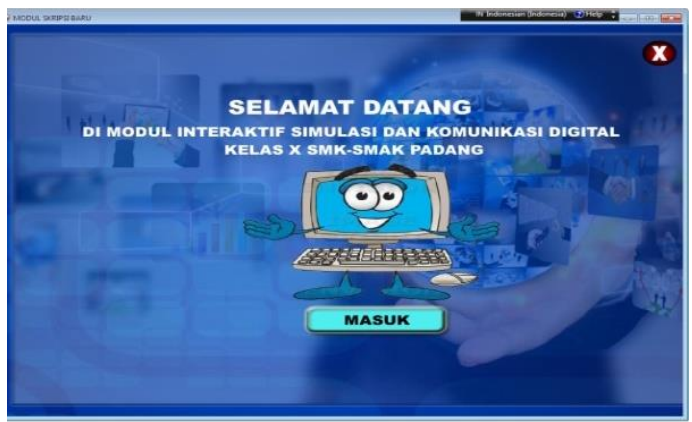

Gambar 3. Halaman Menu Utama

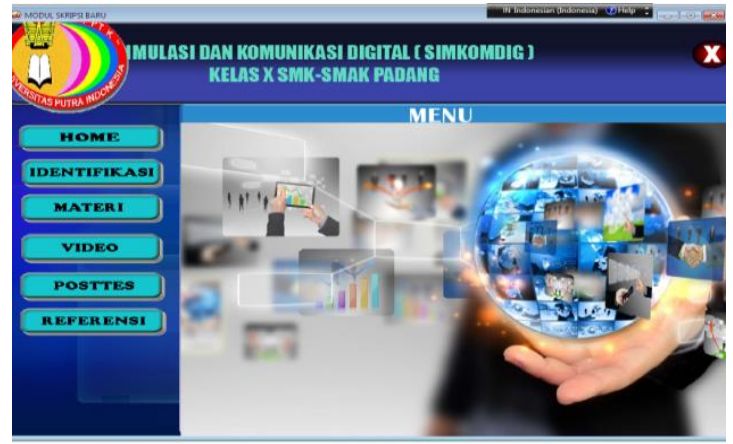

Gambar 4. Halaman Tombol About

Tabel 3. Uji Validitas

\begin{tabular}{|cccc|}
\hline No & $\begin{array}{c}\text { Kelas } \\
\text { Interva } \\
\mathbf{l}\end{array}$ & $\mathbf{f}_{\mathbf{0}}$ & \% f \\
1 & $72-75$ & 5 & 15,15 \\
2 & $76-79$ & 6 & 18,18 \\
3 & $80-83$ & 8 & 24,24 \\
4 & $84-87$ & 10 & 30,3 \\
5 & $88-91$ & 2 & 6,06 \\
\hline
\end{tabular}


125 Pengujian validitas modul interaktif simulasi dan komunikasi digital berbasis macromedia director MX- Rina Sepriana, Rini Sefriani, Indra Wijaya, Pipit Lestari

Uji validitas dilakukan oleh 3 orang validator ahli media. Penilaian dari validator untuk media pembelajaran Sistem Komputer di tinjau dari aspek (1) Kelayakan isi: 90.4\%; (2) Komponen Kebahasaan: 91.00\%; (3) Komponen Penyajian: 89.5\%; (4) Komponen Kegrafikan: 90.3\%. Secara keseluruhan penilaian uji validator terhadap media pembelajaran Sistem Komputer sebesar $90.35,00 \%$, sehingga media pembelajaran tersebut bisa dikatakan sangat valid di gunakan $r$. Untuk memperoleh gambaran yang jelas tentang distribusi skor angket validitas dapat dilihat tabel berikut:

Tabel 4. Distribusi Frekuensi Skor Angket Validitas

\begin{tabular}{|lccc|}
\hline No & Kelas - & F0 & \% F0 \\
& Interval & & \\
1 & $75-80$ & 1 & 33,33 \\
2 & $81-86$ & 1 & 33,33 \\
3 & $87-92$ & 0 & 0 \\
4 & $93-98$ & 1 & 33,33 \\
& Jumlah & $\mathbf{3}$ & $\mathbf{1 0 0}$ \\
\hline
\end{tabular}

Sumber : Pengolahan data mandiri

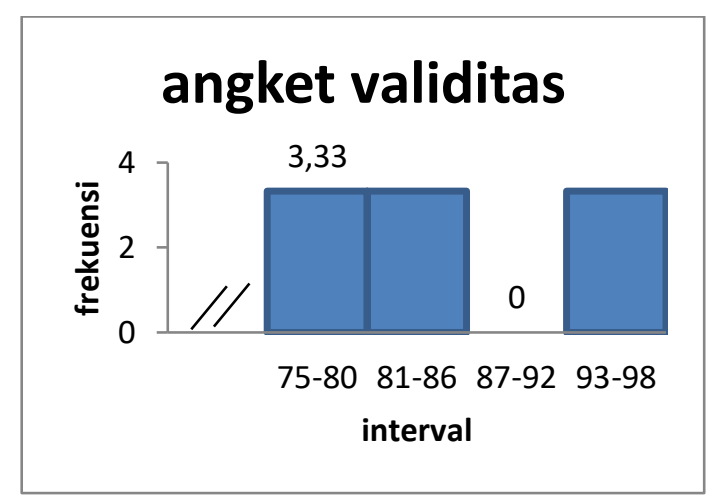

Gambar 5. Histogram Angket Validitas

\section{UCAPAN TERIMA KASIH}

Terima kasih kepada Dekan Fakultas Keguruan dan Ilmu Pendidikan Universitas Putra Indonesia YPTK Padang, ketua lembaga penelitian dan pengabdian kepada Universitas Putra Indonesia YPTK Padang, kepala sekolah dan guru di SMK-SMAK Padang. Semua pihak yang terlibat dalam penelitian ini.

\section{SIMPULAN}

Perancangan dan pembuatan Modul Multimedia interaktif berbasis Macromedia Director $M X$ mengikuti prosedur dan pengembangan (Research and Development) Sugiyono (2014:298). Berdasarkan diskripsi, analisis data, dan pengembangan Modul Multimedia interaktif berbasis Macromedia Director MX dapat disimpulkan Validitas melalui penilaian uji validator terhadap Modul Multimedia interaktif berbasis Macromedia Director MX sebesar $90.35,00 \%$, sehingga tingkat validitas dapat di interprestasikan sangat valid digunakan pada Mata Simulasi dan KomunikasiDigital (SIMKOMDIG) Kelas X SMK-SMAK Padang

\section{DAFTAR PUSTAKA}

Wijaya, I., \& Sefriani, R. (2017). Interactive Modules Based Adobe Director On Computer Assembling Subjects For Vocational Secondary School Students. VOLT: Jurnal Ilmiah Pendidikan Teknik Elektro, 2(2), 73-80.

Wijaya, I., \& Sefriani, R. (2016). Interactive Multimedia CD Design Chemistry Lesson In Concept Training Material and amendment For Class X Vocational High School (SMK). JOURNAL OF DYNAMICS (International Journal of Dynamics in Engineering and Sciences), 1(1).

Sefriani, R., \& Wijaya, I. (2018). Pembuatan Modul Pembelajaran Multimedia Interaktif Berbasis Adobe Director Pada Mata Pelajaran Sistem Operasi Sekolah Menengah Kejuruan. INTECOMS: Journal of Information Technology and Computer Science, 1(1), 60-71.

Sefriani, R., \& Veri, J. (2018). Pengembangan Mobile Learning Berbasis Client Server Pada Mata Pelajaran Simulasi Digital. Jurnal KomtekInfo, 5(3), 61-71.

Sefriani, R., Wijaya, I., \& Radyuli, P. (2018). Development of android based learning media on the subjects of digital photo 
126 Pengujian validitas modul interaktif simulasi dan komunikasi digital berbasis macromedia director MX- Rina Sepriana, Rini Sefriani, Indra Wijaya, Pipit Lestari

composition for vocational high school student. VOLT: Jurnal Ilmiah Pendidikan Teknik Elektro, 3(2).

Jafnihirda, L., Diani, D., \& Sefriani, R. (2019). Modul, 3D Pageflip Profesional, PENGEMBANGAN MODUL PEMBELAJARAN DESAIN GRFAIS BERBASIS 3D PAGEFELIP PROFESSIONAL. JURNAL PTI (PENDIDIKAN DAN TEKNOLOGI INFORMASI) FAKULTAS KEGURUAN ILMU PENDIDIKAN UNIVERSITA PUTRA INDONESIA" YPTK" PADANG, 6(1), 45-54.

Rusman, M. P., \& Cepi, R. (2012). Belajar dan Pembelajaran Berbasis Komputer. Bandung: Alfabeta

Sugiyono. (2014). Metode Penenlitian Kuantitatif, Kualitatif, dan R\&D: Bandung. Alfabeta

Radyuli, P., Sefriani, R. S., \& Qomariah, N. (2019). PEMBELAJARAN INQUIRY MENGGUNAKAN GOOGLE FORM TERHADAP HASIL BELAJAR SIMULASI DAN KOMUNIKASI DIGITAL. EDUKATIF: JURNAL ILMU PENDIDIKAN, 1(2), 56-63.

Purwanto, M. N. (2010). Prinsip-prinsip dan teknik evaluasi pengajaran. Jakarta: Remaja Rosdakarya

Menrisal, M., \& Putri, H. M. (2018). Perancangan dan Pembuatan Media Pembelajaran Berbasis Android Mata Pelajaran Pemrograman Dasar (Studi Kasus Kelas X TKJ SMK Negeri 2 Padang). JURNAL PTI (PENDIDIKAN DAN TEKNOLOGI INFORMASI) FAKULTAS KEGURUAN ILMU PENDIDIKAN UNIVERSITA PUTRA INDONESIA" YPTK" PADANG, 5(2), 21-30.

Menrisal, M., Yunus, Y., \& Rahmadini, N. S. (2019). PERANCANGAN DAN PEMBUATAN MODUL PEMBELAJARAN ELEKTRONIK BERBASIS PROJECT BASED LEARNING MATA PELAJARAN SIMULASI DIGITAL SMKN 8 PADANG. JURNAL KOULUTUS, 2(1), 116.

Menrisal, M., \& Utami, N. R. (2019). Perancangan dan Pembuatan Media Pembelajaran Android pada Mata Pelajaran Simulasi dan Komunikasi Digital. JURNAL PTI (PENDIDIKAN DAN TEKNOLOGI INFORMASI) FAKULTAS KEGURUAN
ILMU PENDIDIKAN UNIVERSITA PUTRA INDONESIA" YPTK" PADANG, 6(1), 1-11.

Radyuli, P., \& Khairani, N. (2019). PERANCANGAN DAN PEMBUATAN MEDIA PEMBELAJARAN BERBASIS ANDROID PADA MATA PELAJARAN SIMULASI DAN KOMUNIKASI DIGITAL (STUDI KASUS KELAS $\mathrm{X}$ SMK-SMAK PADANG). JURNAL PTI (PENDIDIKAN DAN TEKNOLOGI INFORMASI) FAKULTAS KEGURUAN ILMU PENDIDIKAN UNIVERSITA PUTRA INDONESIA" YPTK" PADANG, 6(1), 55-65 